\title{
Sales Control Systems and Salesperson Commitment: The Moderating Role of Behavior Uncertainty
}

\author{
Miao Li ${ }^{1}$, Luluo Peng ${ }^{2, *}$ and Guijun Zhuang ${ }^{3}$ \\ 1 School of Management, Jilin University, Changchun 130022, China; miao@jlu.edu.cn \\ 2 School of Business, Hunan University, Changsha 410082, China \\ 3 School of Management, Xi'an Jiaotong University, Xi'an 710049, China; zhgj@mail.xjtu.edu.cn \\ * Correspondence: pengluluo@139.com
}

Received: 5 March 2020; Accepted: 23 March 2020; Published: 25 March 2020

check for updates

\begin{abstract}
Although sales control has been identified by previous literature as an effective tool to promote salesperson commitment, unclear categorization of the focal variables makes existing findings confounding. This paper aims to provide more nuanced understanding about the relation between sales control systems and salesperson commitment by categorizing sales control into outcome control, activity control, and capability control. Moreover, we explore the moderating role of behavioral uncertainty, which includes sales cycle uncertainty and behavioral content uncertainty. Using a sample of 208 salespersons in China, we find the following results: (1) sales cycle uncertainty weakens the positive impact of outcome control on salesperson commitment and the negative relationship between activity control and salesperson commitment; (2) behavioral content uncertainty strengthens the positive link between outcome control and salesperson commitment and the negative impact of activity control on salesperson commitment; and (3) both sales cycle uncertainty and behavioral content uncertainty strengthen the positive relationship between capability control and salesperson commitment. This research enriches knowledge about sales control systems and offers insights into the important contextual role of behavior uncertainty that has been largely ignored by prior research in the sales force control literature.
\end{abstract}

Keywords: sales force control systems; behavior uncertainty; salesperson commitment; outcome control, activity control; capability control

\section{Introduction}

Salespersons play the role of immediate interface between the organization and the customers. They contribute significantly to the growth and sustainable survival of companies by generating sales volumes and developing long-term relations between end-customers and companies [1-3]. This is especially true for industrial firms, where the sales force is a unique organizational unit that produces output sales [4]. The turnover of salespeople usually results in economic loss due to customer defection, and thus harms the sustainable competitive advantage of the companies [5]. To reduce the costs caused by sales force turnover, firms could increase salespersons' commitment to the organizations, which is regarded as the prerequisite for enhancing end-performance, reducing opportunism, promoting organization citizenship behavior, and improving other work outcomes [6-8]. Prior literature suggests that the proper utilization of sales force control systems is one method of increasing organizational commitment [9-11]. However, despite the great efforts made by previous studies, at least two limitations regarding the link between sales control systems and salesperson commitment remain.

First, the majority of researchers did not categorize sales force controls clearly in their research about the relation between sales controls and organization commitment. Prior literature has exerted great efforts in investigating how to perform sales force controls successfully [12-14]. Many researchers 
classified sales force controls into those monitoring the final outcomes of a process (outcome control) and those monitoring individual stages in the process (behavior control) [15-17]. They found that sales force controls could affect job satisfaction, opportunism, adaptive selling efforts, sales performance, and so on, but the empirical results remain conflicting. For instance, outcome control has been reported to enhance job satisfaction and performance [10], to hurt trust and job performance [18], and have no direct impact on job-related performances [19]. Behavior control has also been reported to have positive, negative or insignificant relation with salespeople's work outcomes [20]. Challagalla and Shervani [21] further divided behavior control into activity control and capability control, in which activity control focuses on the enforcement of specific activities and capability control emphasizes on the development of skills and abilities, and they argued that activity control and capability control have different or even apposing functions in sales force. However, to the best of our knowledge, almost all the studies on the link between sales controls and organization commitment treated behavior control as an uni-dimensional construct rather than split it into capability control and activity control $[12,17]$. That might lead to misleading conclusions.

Second, to clarify the inconsistency among prior research about the direct effects of sales controls on work outcomes, prior research has introduced a series of moderating factors, such as environmental uncertainty [22,23], risk aversion [24], salesperson location [25], and other elements [20]. These findings suggest some potential implications to shed light on the proper way to execute sales force control system in different contexts. However, one important contextual factor, behavioral uncertainty, i.e., the degree of difficulty associated with evaluating salesperson's contribution [26], remains unexplored. As a key construct in transaction cost theory, behavioral uncertainty is crucial in choosing the optimal control structure, and it might function quite differently from environmental uncertainty [27]. Therefore, exploring the impact of behavioral uncertainty in sales force control system is of vital importance. What's more, despite the recognition that behavioral uncertainty might include different types, such as evaluative cycle and information content [28], behavior uncertainty has been theorized as a monolithic concept. Absent is a more fine-grained approach that uncovers distinctive forms of behavior uncertainty.

To fill in the aforementioned research gaps, this paper explicitly models the relationship between three sales control mechanisms (outcome, activity and capability controls) and salesperson commitment and tests the relationship empirically in China. Moreover, based on transaction cost theory, we introduce behavioral uncertainty as the moderator which has been largely ignored by prior literature. In addition, we further divide behavior uncertainty into two dimensions, sales cycle uncertainty and behavioral content uncertainty, which could provide us better understanding of the effectiveness of sales force control mechanism.

\section{Conceptual Background}

\subsection{Sales Control Systems}

Sales force control system refers to the key instrument that managers have to influence salespeople's attitudes and behaviors in order to attain the organizational objectives [9]. Anderson and Oliver's [29] seminal work first classified sales force controls into outcome control and behavior control. Outcome control relies straightly on objective measures of results, such as a salesperson's sales volume, revenue, or quota attainment, and involves relatively little monitoring of salespeople by management. In contrast, behavioral or process control focuses on salesperson's job efforts, such as activities, knowledge and sales tactics, and typically involves extensive monitoring and directing feedback from managers about their behaviors. Prior literature yields a mixed link between behavior control and salesperson work outcomes. From the positive view, previous researchers argued that under behavior-based control, salespersons are likely to get the chance to communicate with their managers more frequently, and managers will thus get more information about salespersons' effort during the selling process and provide feedback to improve salespersons' selling skills. This will increase the salesperson's trust in the organization and satisfaction towards the job [30,31]. On the other hand, the negative view 
argues that since behavior control requires frequent evaluation and top-down determination of routine activities, salesperson will develop negative feelings and senses of disgust towards their managers [32]. Thereby, salesperson's job motivation and enthusiasm will be discouraged.

To clarify the link between behavior control and work outcomes, Challagalla and Shervani [21] categorize further behavior control into activity and capability control. Activity control indicates the specification and monitoring of the routine activities that a salesperson is expected to perform on a regular basis, such as number of customer calls and type of services to perform. Sometimes managers will perform certain rewards and punishment as reinforcements. Whereas capability controls emphasize the development of sales-related knowledge and skills, which involves managers' active efforts in setting capability goals, training, and providing diagnostic feedback. However, some later studies, e.g., [9,17], including the latest meta-analysis studies [31], still treated behavior control as an uni-dimensional construct instead of splitting it into capability control and activity control, which might lead to confusing conclusions.

\subsection{Salesperson Commitment}

Commitment plays a critical role in determining a salesperson's job satisfaction, intention to leave and long-term end-performance, and thus receives significant attention in sales management research literature [6-8]. Following Mowday and his colleagues [33], this paper defines salesperson commitment as the relative strength of a salesperson's identification with and involvement in his working organization. It can be generally categorized into three sub-types, namely, affective commitment, continuance commitment and normative commitment [34]. Affective commitment refers to the salesperson's sense of belonging and attachment to the working organization. Continuance commitment refers to the salesperson's perceived cost associated with potential turnover; normative commitment is the salesperson's feeling of moral obligation to remain in the working organization [34]. Compared with the latter two types of commitment, affective commitment is widely regarded as more effective to measure organization commitment [35]. Further, affective commitment is also reported to have direct and indirect impacts on continuance and normative commitment [36], and thus this paper focuses on affective commitment. Moreover, prior literature has exerted great efforts in exploring the antecedents of salesperson commitment [37-39]. They have identified the utilization of sales control systems as one important method [5,11]. However, to the best of our knowledge, few researchers have distinguished activity control from capability control.

\subsection{Behavior Uncertainty}

To make correct decisions about sales force control implementation, managers should assess the environmental and behavioral uncertainty [22]. Environmental uncertainty refers to "unanticipated changes in circumstances surrounding an exchange" [40], and behavioral uncertainty, as stated by Williamson [27], indicates the degree of difficulty associated with assessing the contribution of transaction partner (the salesperson). Previous research has focused mainly on the impact of environmental uncertainty on control structure effectiveness $[23,24,26]$, and found that environmental uncertainty is a vital contextual factor of the relationship between sales controls and work outcomes. Particularly, under high levels of environmental uncertainty, salespersons will perceive a higher level of job satisfaction and get better performance under outcome control compared with behavior control. In contrast, under lower levels of environmental uncertainty, salespersons will perceive a higher level of job satisfaction and get better performance under behavior control compared with outcome control.

Behavioral uncertainty is defined as the degree of difficulty associated with assessing the contribution of transaction partners (salesperson) according to the transaction cost theory literature [27]. Compared with studies on environmental uncertainty, studies about behavioral uncertainty are far fewer, and operationalizations of this construct are even fewer [41]. Several researchers define behavioral uncertainty as the ambiguity to measure past and present individual performance with standardized evaluations, such as lack of reasonable performance standards and subjective evaluation 
of individual salespeople's results [42,43]. This paper calls this kind of assessment ambiguity as behavioral content uncertainty, which reflects the degree to which the manager could not assess an employee's contribution and performance accurately [44]. Moreover, some other researchers treat the length of sales cycle as another indicator of behavioral uncertainty [45], since it will be hard to measure individual outputs if the task takes long time to complete [46,47]. In this paper, we use the concept of sales cycle uncertainty to capture this kind of behavioral uncertainty, and define it as the difficulty to restrain a salesperson's sales cycle to a specified time period. Literature in the field of behavioral economy also contains similar categorizations, such as cycle uncertainty and evaluative information uncertainty [28].

\section{Research Hypotheses}

\subsection{Main Effect of Outcome Control}

Outcome control involves setting output goals, monitoring, and providing feedback on output performance. According to the goal theory, clear outcome-oriented goals will motivate salespersons to directly attend to the goal-relevant activities and focus on tasks leading to achievement of those goals [48]. This can push salespersons to accept the goals and values of the organizations, and develop a sense of identification with the organization [49]. Further, the feedback from managers about the end-performance could improve salespersons' willingness to contribute to the growth of the organizations [50]. Furthermore, outcome control allows salespersons with freedom to choose any method that can attain the goal, and thus increases their willingness to exert efforts on behalf of the organization and enhances their sense of organizational responsibility [51]. Prior literature also provides empirical support about the positive relation between outcome control and salesperson commitment [20]. Therefore, the hypothesis is as follows:

Hypothesis 1a (H1a). Outcome control positively affects salesperson commitment.

\subsection{Main Effect of Activity Control}

Activity control focuses on regulating the activities that a salesperson is expected to perform. To perform activity control, managers specify the activities the salesperson should engage on a regular basis, monitor their actual activities and administrate rewards or punishment sometimes [52]. This paper proposes a negative link between activity control and salesperson commitment for the following three reasons. First, frequent evaluation and structured daily activities such as specifying call rates and submitting call feedback might decrease salespersons' sense of autonomy, thereby reducing their work enthusiasm. Second, routine activities arranged by managers might decrease the sales reps' sense of responsibility due to reduced task-related pressure and risk. Third, top-down determination of routine activities might cause negatively emotional responses and dis-satisfaction towards the work environment [32]. The salespersons' work motivation would be thereby discouraged. Therefore, the hypothesis is as follows:

Hypothesis $\mathbf{1 b} \mathbf{( H 1 b ) . ~ A c t i v i t y ~ c o n t r o l ~ n e g a t i v e l y ~ a f f e c t s ~ s a l e s p e r s o n ~ c o m m i t m e n t . ~}$

\subsection{Main Effect of Capability Control}

Capability control includes setting goals for the level of skills and abilities salespersons must possess, monitor their skills and abilities, provide guidance for improvement if needed, and perform reinforcement such as reward and punishment [53]. Managers are required to provide training, apprenticeships, mentoring, coaching, and job enrichment programs to implement capability control [52]. As suggested previously, sales training could increase salesperson's professional skills, 
and salespersons who possess a variety of job skills usually have stronger job satisfaction and work enthusiasm [54]. Further, frequent feedback from immediate managers about selling tactics could enhance the relationship between sales force and the managers, and further strengthen the salespersons' sense of attachment to the organizations. Salespersons could feel more responsible to ensure the survival and growth of the organization [5]. A lack of sufficient guidance and support from the managers, however, will lead the salespeople to become dis-satisfied about the job and frustrated towards the work environment [36]. Therefore, we hypothesize that:

Hypothesis 1c (H1c). Capability control positively affects salesperson commitment.

\subsection{Contextual Effect of Behavioral Uncertainty—Sales Cycle Uncertainty}

Sales cycle uncertainty reflects the difficulty to monitor and evaluate salespersons' individual outcomes within a short or specified period. We suppose sales cycle uncertainty could negatively moderate the positive relationship between outcome control and salesperson commitment. When sales cycle uncertainty is high, it takes longer time for a salesperson to fulfill the sales order. Under this context, an outcome-based control will put much pressure on the salespersons by emphasizing on the short-term goals. Being unable to meet the demands of the manager, salespersons may thereby be frustrated and discouraged, resulting in decline in job satisfaction and commitment to the organizations [18]. Furthermore, since the sales orders are difficult to be completed within a required time period, outcome-based rewards will be less attractive to the salespersons, i.e., the punishment would also be considered as unfair to those who paid efforts but were still waiting for outcomes. The sales force thereby would yield low level of work motivation. Therefore, the positive impact of outcome control on salesperson commitment will be weakened under high level of sales cycle uncertainty. In contrast, if the sales tasks can be completed within a relatively acceptable period, short-term goals will be effective to motivate salespersons to work actively and participate enthusiastically. The rewards based on individual achievements will increase their willingness to perform better. Therefore, we propose the following hypothesis:

Hypothesis 2a (H2a). Sales cycle uncertainty weakens the positive relationship between outcome control and salesperson commitment.

We suppose that sales cycle uncertainty would weaken the negative relationship between activity control and commitment for two reasons: First, activity control under high level of sales cycle uncertainty can function as an effective tool to monitor salesperson's perquisite consumption. Salespersons may commit slack or dysfunctional behavior and seek excuses for poor performances if the task is difficult to fulfill. When the time period for a salesperson to complete the sales order is lengthy, monitoring salespersons' daily efforts will effectively decrease information asymmetry, restrain salespersons' slack or dysfunctional behaviors, and lead them to focus more on improving work performance instead of seeking perquisite consumption [46]. Second, activity control under high sales cycle uncertainty can enhance salesperson's work enthusiasm. During the tedious sales cycle to wait for customer's orders, in time feedback and rewards based on individual efforts will enhance salespersons' sense of esteem. This would enhance job satisfactions and motivation. In contrast, if the salesperson could effortlessly complete sale orders within the required time period, he might probably have established mature selling skills and get used to sell products in his own way. Top-down determination of routine activities may be regarded as redundant and even provoke the salespersons' disgust towards his manager. Job satisfaction and organization commitment will thus be declined. Therefore, the hypothesis is:

Hypothesis $\mathbf{2 b}(\mathbf{H} \mathbf{2 b})$. Sales cycle uncertainty weakens the negative relationship between activity control and salesperson commitment. 
We argue that sales cycle uncertainty has a positive moderating effect on the relationship between capability control and salesperson commitment. Because the risk of gaining a sales order will be enlarged with a longer period of the sales cycle, salespersons may encounter problems during their sales process. Under capability control, salespersons are more likely to frequently communicate with their managers, and thereby solve problems more efficiently [52]. Consequently, job satisfaction and sense of attachment to the organization will thus be improved compared with those under low capability control. Therefore, we propose the following hypothesis:

Hypothesis 2c (H2c). Sales cycle uncertainty strengthens the positive relationship between capability control and salesperson commitment.

\subsection{Contextual Effect of Behavioral Uncertainty-Behavioral Content Uncertainty}

The behavioral content acts as the principle of guidance according to which the manager punishes or rewards the employees. Behavioral content uncertainty reflects the degree of difficulties to appropriately assess salespersons' efforts-related contribution by the manager with reasonable principles [44]. We argue that behavioral content uncertainty strengthens the positive relationship between outcome control and salespersons' commitment. As indicated by prior literature, the usefulness of control systems depends on managers having a relatively complete knowledge of the transformation process and a strong ability to effectively set indicators to measure employee's outputs or endeavors [55]. However, if the managers have poor capability to observe and assess certain aspect of individual contribution, the punishments and rewards related will be less effective and unfair. Compared with behavior control, outcome control emphasizes little on specific routine activities but places much weight on the extent to which the organizational goals such as sales volumes get achieved. Evaluating individual contribution according to final end-outcomes rather than the specific procedures might be fairer and more reasonable under high behavioral content uncertainty. On the contrary, if behavioral content uncertainty is low, the indicators measuring individual contribution would be rational and convincing, which in turn ensures the effectiveness of behavior control and decreases the reliance on outcome control. Therefore, we hypothesize that:

Hypothesis 3a (H3a). Behavioral content uncertainty strengthens the positive relationship between outcome control and salesperson commitment.

We argue that behavioral content uncertainty strengthens the negative impact of activity control on salespersons' commitment to the organizations. The belief that activity direction acts as an effective tool pertains to the case that the performance of those activities are relative clear [56] However, if the manager has difficulties to recognize the discrepancy between salespersons' behaviors and their required process, the implementation of activity control will be invalid, which induces salespersons' dysfunctional or slack behavior and reduces sense of organizational responsibility [46]. Further, if the manager evaluates salespersons in a subjective way with no observable indicators, the required process may be considered as somewhat unreasonable and unconvincing. That could further decrease salespersons' trust in their manager and work enthusiasm. In addition, if rewarding and punishing are determined only according to sales force activities but not by tracing their individual effort equally, perceived unfairness would decrease salespersons' commitment to firm [56]. Therefore, with the increase of behavioral uncertainty, the negative relation between activity control and commitment will be strengthened. In contrast, activity control under low level of behavioral content uncertainty could to some degree be effective in guiding sales force to generate desired outputs, thereby increasing salespersons' work enthusiasm and decreasing the negative impact on salesperson commitment. Therefore, we hypothesize that: 
Hypothesis $\mathbf{3 b} \mathbf{( H 3 b ) . ~ B e h a v i o r a l ~ c o n t e n t ~ u n c e r t a i n t y ~ s t r e n g t h e n s ~ t h e ~ n e g a t i v e ~ r e l a t i o n s h i p ~ b e t w e e n ~ a c t i v i t y ~}$ control and salesperson commitment.

Finally, we posit that behavioral content uncertainty has a positive moderating impact between capability control and salesperson commitment. Prior evidence suggested that salespeople do not equate the acquisition of skills with the capability controls that are often implemented by management [50]. The harder the manager can observe and evaluate salesperson's individual effort, the more nurture s/he would provide to the subordinates to decrease their sense of unfairness, and improve their working enthusiasm and sense of attachment to the organizations. Thus, we hypothesize that:

Hypothesis 3c $\mathbf{( H 3 c ) . ~ B e h a v i o r a l ~ c o n t e n t ~ u n c e r t a i n t y ~ s t r e n g t h e n s ~ t h e ~ p o s i t i v e ~ r e l a t i o n s h i p ~ b e t w e e n ~ c a p a b i l i t y ~}$ control and salesperson commitment.

The conceptual model of this paper is presented in Figure 1.

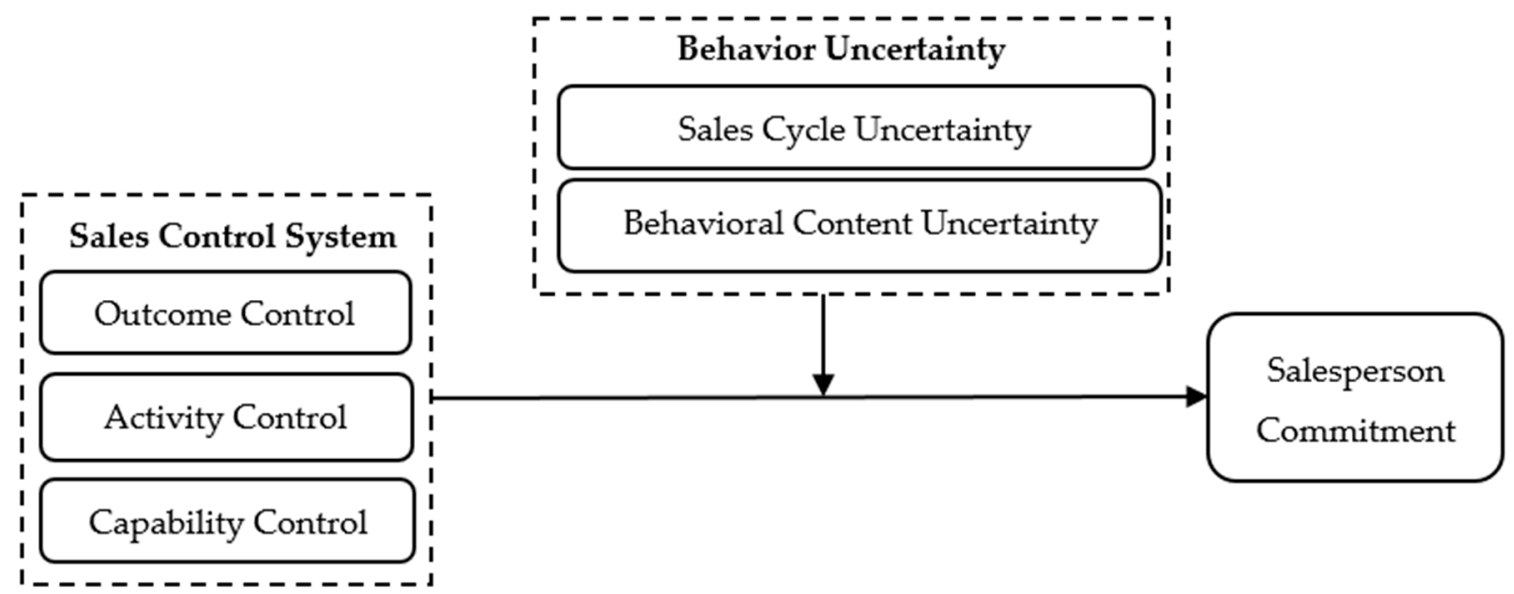

Figure 1. Conceptual Model.

\section{Empirical Analysis}

\subsection{Sample and Data Collection}

We utilize a cross-sectional survey method for data collection. Chinese manufacturing sector represents an appropriate research setting because of its sufficient variance in the deployment of activity, capability, and outcome control [57]. We obtained the list of sample firms from the Chinese People's Political Consultative Conference (CPPCC), selecting Jilin, Beijing and Guangdong provinces where the manufacturing firms are relatively well-developed, and the employees are largely delegated to output sales benefits [43]. Of the selected 183 firms, 64 firm managers agreed to participate in the interview and sent the mailed questionnaires to their sales reps. A total of 355 salespersons completed the questionnaires and among them 208 were valid, resulting a net response rate of $58.59 \%$. Data was collected from late June to mid-September in 2019.

The final sample covers a wide range of industries, including textiles (32.03\%), electronics $(25.00 \%)$, food $(19.23 \%)$, furniture $(14.42 \%)$, and others $(9.32 \%)$, which ensures sample diversity. Each company submitted 1-8 salespersons' responses. Further, $58.2 \%$ of the respondents are female. $52 \%$ of the respondents are below 30 years old, $26.4 \%$ are between 30 to 34 years, $21.6 \%$ are above 35 years old. With regard to the education level, $55.8 \%$ of the respondents have a bachelor's degree or above, $22.6 \%$ have junior college degree, and $21.6 \%$ have high school degree or below. 


\subsection{Measurement}

All constructs in our study were measured with scales adapted from existing literature. To create the Chinese version of the measures, we followed the conventional translation-back- translation procedure suggested by Brislin and Richard [58]. First, we translate the scales from English to Chinese, and then three other scholars were invited to back-translate the items from Chinese to English. All of us reviewed the translation and back-translation and resolved any issues occur through discussion. Before finalizing the survey instrument, we pretested it on around 30 salespersons, based on which we made some necessary modifications to enhance clarity and face validity. All the measures use 5-point Likert scales from $1=$ "strongly disagree" to $5=$ "strongly agree". The measuring items for each construct are presented in Appendix A.

This study adapts the measure of outcome control from Jaworski and MacInnis [59] to assess the degree to which managers monitor sales force based on the final outcomes of a process. The three-item scale measures the extent to which managers supervise salespeople based on profit goals and established sales volume and provide punishment as reinforcements. Following Challagalla and Shervani [21], the study measures activity control with three items reflecting the manager's supervision over salespersons' routine activities. The three items indicate the degree to which managers monitor sales force via the specific activities that they are expected to perform and provide rewards or punishments accordingly. The measure of capability control, adapted from Challagalla and Shervani [21], captures the degree to which the manager values the development of salespeople's skills and knowledge, and measures it with the manager's related efforts such as providing guidance, suggestion and feedback on improving salespersons' selling skill and tactics.

Sales cycle uncertainty refers to the difficulty to measure individual sales performance within a specified time period, and prior study typically measured it with a single indicator of the length of sales cycle [44]. Following Churchill's [60] instructions, this study adapted his scale to form a three-item scale which reflects the degree to which a sales rep's can restrain his sales cycle to a limited and certain time period. Using a pilot study of 55 salespersons, we found that all the three items converge in one dimension in EFA analysis with factor loadings above $0.8(0.83,0.88$, and 0.87$)$. Using a scale adapted from Stump and Heide [42], this study measures behavioral content uncertainty with the degree to which a manager could assess a sales rep's contribution objectively and reasonably.

Following Meyer and Allen [61], the study measures salesperson commitment with three items which reflect the salespersons' sense of belonging and attachment to the organizations. Besides, we also control the effects of salesperson characteristics, such as age (in years), gender $(0=$ female, $1=$ male), education ( 1 =high school graduate and below, 2 = junior college, $3=$ Bachelor degree, $4=$ Masters and $\mathrm{PhD}$ degree) and working experience in the same industry (in years), since they may affect salespersons' feelings about work climate and job satisfaction $[62,63]$.

\subsection{Results}

\subsubsection{Reliability and Validity Test}

Table 1 provides the means, standard deviations, and correlations between the constructs. 
Table 1. Descriptive statistics and bivariate correlation mix.

\begin{tabular}{|c|c|c|c|c|c|c|c|c|c|c|}
\hline Variable & 1 & 2 & 3 & 4 & 5 & 6 & 7 & 8 & 9 & 10 \\
\hline 1 Outcome Control (OC) & 0.76 & & & & & & & & & \\
\hline 2 Activity Control (AC) & $-0.34^{* *}$ & 0.77 & & & & & & & & \\
\hline 3 Capability Control (CC) & $0.19^{* *}$ & $-0.26^{* *}$ & 0.75 & & & & & & & \\
\hline 4 Sales Cycle Uncertainty (SCU) & -0.08 & 0.03 & $0.22^{* *}$ & 0.75 & & & & & & \\
\hline $\begin{array}{l}5 \text { Behavioral Content Uncertainty } \\
\text { (BCU) }\end{array}$ & -0.09 & 0.06 & -0.01 & -0.02 & 0.79 & & & & & \\
\hline 6 Salesperson Commitment & $0.34^{* *}$ & $-0.38^{* *}$ & $0.33^{* *}$ & 0.01 & -0.06 & 0.78 & & & & \\
\hline 7 Gender & $-0.12+$ & 0 & -0.01 & -0.02 & -0.04 & $-0.20^{* *}$ & - & & & \\
\hline 8 Age & 0.09 & 0.01 & 0.08 & -0.11 & -0.02 & $0.12+$ & -0.05 & - & & \\
\hline 9 Education & 0.03 & 0.06 & -0.03 & 0.07 & 0.05 & $-0.19^{* *}$ & 0.03 & -0.06 & - & \\
\hline 10 Working Experience & -0.05 & $0.14 \dagger$ & -0.04 & -0.07 & 0.01 & 0.06 & 0.04 & $0.21^{* *}$ & -0.01 & - \\
\hline Mean & 3.25 & 3.02 & 3.32 & 3.22 & 3.55 & 3.49 & 0.42 & 2.55 & 2.45 & 2.61 \\
\hline Std. deviation & 0.80 & 1.07 & 0.77 & 1.02 & 0.93 & 0.91 & 0.49 & 1.11 & 0.95 & 0.96 \\
\hline
\end{tabular}

Note: $\mathrm{N}=208,+p<0.1$ (two-tailed), ${ }^{*} p<0.05$ (two-tailed), ${ }^{* *} p<0.01$ (two-tailed). Diagonal elements (bold) are the square root of the variance shared between the constructs and their measures.

We conducted a confirmatory factor analysis (CFA) to assess the reflective measure's reliability and validity (see Appendix A). The composite reliability (CR) scores for all construct exceed 0.8 , and all the average variance extracted (AVE) values are above 0.50 . These values indicate a good convergent validity. The square root of AVE in each case exceeds the squared correlation between any pair of constructs, thus providing a satisfactory discriminant validity [64]. The model was satisfactory $\left(\chi^{2} / \mathrm{df}\right.$ $=1.43, \mathrm{p}<0.001$; confirmatory fit index $[\mathrm{CFI}]=0.97$; incremental fit index $[\mathrm{IFI}]=0.97$; Tacker-Lewis index $[\mathrm{TLI}]=0.96$; root mean square error of approximation $[\mathrm{RMSEA}]=0.045)$. The Cronbach's alpha coefficients for each factor exceed 0.8 , and all standardized factor loadings exceed 0.7. Thus, the constructs for the model have good reliability and validity.

\subsubsection{Common Method Variance}

This study employs Harmon's one-factor test [64] to test the potential existence of common method variance. The results reveal that six factors with eigenvalues account for $75.32 \%$ of the total variance. The first factor only explains $13.60 \%$ of the total variance. In addition, this study also employs a single-factor approach using structural equation modeling (SEM) analysis by setting all items to load on a single factor [65]. The model is unacceptable $\left(\chi^{2} / \mathrm{df}=8.37, p<0.001\right.$; CFI $=0.35$; IFI $=0.36$; $\mathrm{TLI}=0.26$; RMSEA $=0.16$ ). Both tests suggest that common method variance is not a concern.

\subsubsection{Hypotheses Test}

Table 2 presents the hierarchical regression analysis results of the models. This study evaluates the variance inflation factor (VIF) and tolerance value to check the potential existence of multicollinearity among the variables [66]. The values of VIF in all regression models ranged between 1.004 and 1.405 and the tolerance values ranged from 0.712 to 0.996 . Thus, multicollinearity is not a concern.

Model 1 includes the control variables in a linear regression model, Model 2 adds the independent variables, and Model 3 features all the interaction terms. Following Aiken and West's suggestions [67], the values of the variables in the interaction effects were first mean-centered before the regression analysis. 
Table 2. Regression Results.

\begin{tabular}{|c|c|c|c|}
\hline \multirow{2}{*}{ Variables } & \multicolumn{3}{|c|}{ Dependent Variable: Salesperson Commitment } \\
\hline & Model 1 & Model 2 & Model 3 \\
\hline \multicolumn{4}{|c|}{ Control Effects } \\
\hline Gender & $-0.19^{* *}$ & $-0.17^{* *}$ & $-0.12^{*}$ \\
\hline Age & 0.09 & 0.05 & 0.09 \\
\hline Education & $-0.18^{* *}$ & $-0.17^{* *}$ & $-0.13^{*}$ \\
\hline Working Experience & 0.04 & $0.10+$ & 0.06 \\
\hline \multicolumn{4}{|c|}{ Simple Effects } \\
\hline OC & & $0.20 * *$ & $0.14^{*}$ \\
\hline $\mathrm{AC}$ & & $-0.26^{* *}$ & $-0.14^{*}$ \\
\hline $\mathrm{CC}$ & & $0.22^{* *}$ & $0.16^{* *}$ \\
\hline \multicolumn{4}{|c|}{ Moderating Effects } \\
\hline SCU & & & 0.04 \\
\hline OC $\times$ SCU & & & $-0.12^{*}$ \\
\hline $\mathrm{AC} \times \mathrm{SCU}$ & & & $0.14^{*}$ \\
\hline $\mathrm{CC} \times \mathrm{SCU}$ & & & $0.17^{* *}$ \\
\hline $\mathrm{BCU}$ & & & 0.05 \\
\hline $\mathrm{OC} \times \mathrm{BCU}$ & & & $0.20^{* *}$ \\
\hline $\mathrm{AC} \times \mathrm{BCU}$ & & & $-0.17^{* *}$ \\
\hline $\mathrm{CC} \times \mathrm{BCU}$ & & & $0.13^{*}$ \\
\hline Adjusted $\mathrm{R}^{2}$ & 0.07 & 0.29 & 0.44 \\
\hline$\Delta R^{2}$ & & 0.22 & 0.15 \\
\hline $\mathrm{F}$ & $4.74^{* *}$ & $13.04^{* *}$ & $11.95^{* *}$ \\
\hline
\end{tabular}

Note: $\mathrm{N}=208,+p<0.1$ (two-tailed), ${ }^{*} p<0.05$ (two-tailed), ${ }^{* *} p<0.01$ (two-tailed), (t value).

\section{Main Effects}

As the results in Model 1 shows, the control variables account for only $7 \%$ of the variance in salespersons commitment. Gender $(\beta=-0.19, p<0.01)$ and education level $(\beta=-0.18, p<0.01)$ have positive and significant impacts on salesperson commitment. The addition of the focal independent variables in Model 2 results in an increase of $0.22(p<0.01)$ in R-square value. The results confirm the positive impacts of outcome control $(\beta=0.20, p<0.01)$ and capability control $(\beta=0.22, p<0.01)$, as well as negative impact of activity control $(\beta=-0.26, p<0.01)$ on salesperson commitment, which support $\mathrm{H} 1 \mathrm{a}, \mathrm{H} 1 \mathrm{c}$, and $\mathrm{H} 1 \mathrm{~b}$ respectively.

\section{Moderating Effects of Sales Cycle Uncertainty}

Compared with Model 2, the adjusted R-square value in Model 3 increases by $0.15(p<0.01)$ after adding the moderators and the interaction terms, thus providing support to the significant moderating effects of sales cycle uncertainty and behavioral content uncertainty. For further interpretation, in Figure 2, the paper also plots the effects of sales force control systems on salesperson commitment for low and high levels of each moderator following Aiken and West's approach [68].

$\mathrm{H} 2 \mathrm{a}, \mathrm{H} 2 \mathrm{~b}$, and $\mathrm{H} 3 \mathrm{c}$ posit that sales cycle uncertainty moderates the relationship between sales force controls and salesperson commitment. H2a predict that sales cycle uncertainty weakens the positive relation between outcome control and commitment. The results in Model 3 show that the interaction effect between sales cycle uncertainty and outcome control is significantly negative $(\beta=-0.12, p<0.05)$. Panel A in Figure 2 also reveals that outcome control negatively affects salesperson commitment when sales cycle uncertainty is high $(\beta=-0.51, p<0.05)$ but positively affects commitment when it is low ( $\beta=0.19, p<0.05)$, in line with $\mathrm{H} 2 \mathrm{a}$. H2b suggests that sales cycle uncertainty weakens the negative impact of activity control on salesperson commitment. The coefficient for the interaction between sales cycle uncertainty and activity control is significant and positive $(\beta=0.14, p<0.05)$. In Panel $\mathrm{B}$, Figure 2 , when sales cycle uncertainty is low, activity control relates negatively to salesperson commitment 
( $\beta=-0.12, p<0.05)$. However, when sales cycle uncertainty is high, the impact of activity control on salesperson commitment is positive $(\beta=0.33, p<0.1)$, thus supporting $\mathrm{H} 2 \mathrm{~b}$. In line with $\mathrm{H} 2 \mathrm{c}$, we find that sales cycle uncertainty could strengthen the positive link between capability control and sales rep's commitment $(\beta=0.17, p<0.01)$. Figure 2 , Panel $C$ also reports stronger positive impact of capability control on commitment when sales cycle uncertainty is high $(\beta=0.46, p<0.01)$ than when it is low $(\beta=0.28, p<0.01)$. Thus, $\mathrm{H} 2 \mathrm{c}$ is supported.

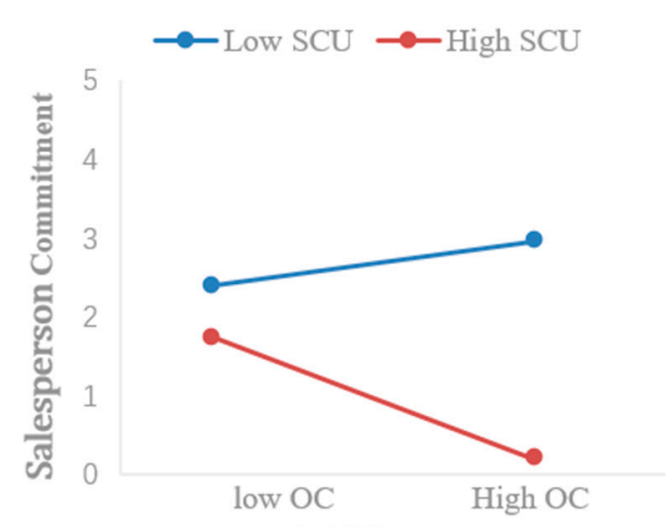

A: $\mathbf{H 2 a}$

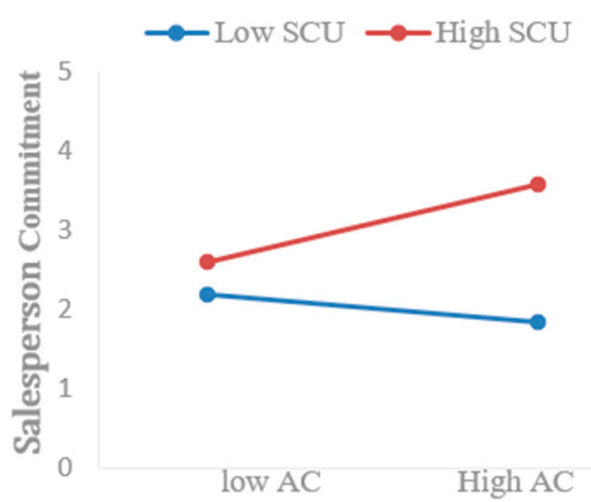

B: H2b

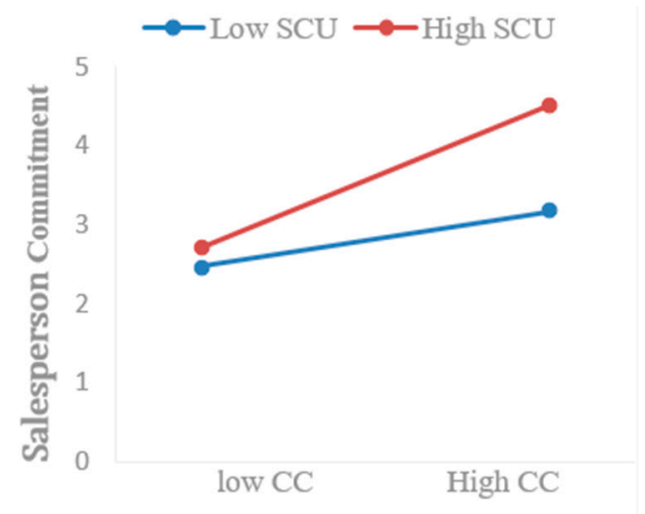

$\mathrm{C}: \mathrm{H} 2 \mathrm{c}$

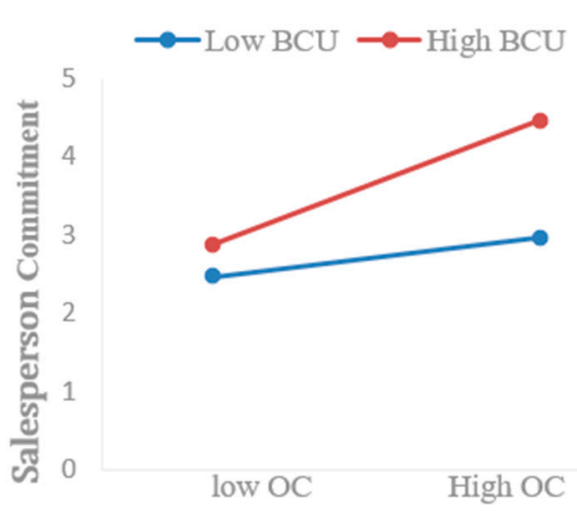

D: H3a

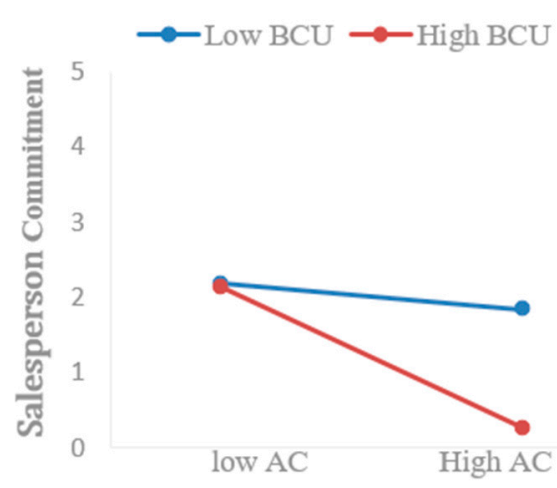

E: H3b

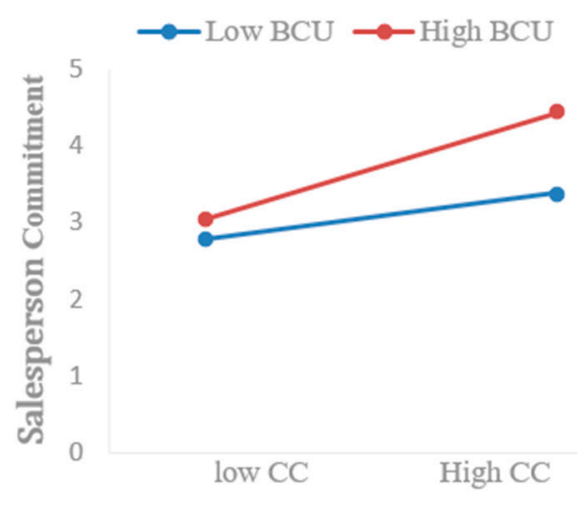

F: H3c

Figure 2. (A-C) moderating effect of sales cycle uncertainty on the relation between outcome control, activity control, capability control and sales person commitment respectively; (D-F) moderating effect of behavioral content uncertainty on the relation between outcome control, activity control, capability control and sales person commitment respectively.

$\mathrm{H} 3 \mathrm{a}, \mathrm{H} 3 \mathrm{~b}$, and $\mathrm{H} 3 \mathrm{c}$ examine the moderating effects of behavioral content uncertainty between sales force controls and salesperson commitment. In line with H3a which predicts that behavioral 
content uncertainty strengthens the positive impact of outcome control on commitment, the results of Model 3 report positive and significant interaction effect between outcome control and behavioral content uncertainty $(\beta=0.20, p<0.01)$. As Figure 2 , Panel $\mathrm{D}$ suggests, outcome control has a stronger positive impact on salesperson commitment when behavioral content uncertainty is high $(\beta=0.53$, $p<0.01)$ than when it is low $(\beta=0.17, p<0.01)$. Thus, H3a is supported. In support of H3b, we find that behavioral content uncertainty strengthens the negative relationship between activity control and salesperson commitment $(\beta=-0.17, p<0.01$ ). Figure 2 , Panel $\mathrm{E}$ also shows that the negative impact of activity control on salesperson commitment is stronger when behavioral content uncertainty is high $(\beta=-0.46, p<0.01)$ than when it is low $(\beta=-0.16, p<0.1)$. Regarding the interplay between capability control and behavioral content uncertainty, in line with our prediction that it could increase salesperson commitment, the results in Model 3 indicate that this moderating effect is significantly positive $(\beta=0.13, p<0.05)$, thus supporting H3b. Panel F in Figure 2 also reports larger positive impact of capability control on salesperson commitment when behavioral content uncertainty is high $(\beta=0.45, p<0.01)$ than when it is low $(\beta=0.26, p<0.01)$.

\section{Discussion and Conclusions}

\subsection{Main Findings}

The purpose of this research is to investigate the moderating role of two kinds of behavioral uncertainties-sales cycle uncertainty and behavioral content uncertainty on the relationship between sales force controls (outcome, activity and capability) and salesperson commitment. With a sample of 208 salespersons in China, all the nine hypotheses are supported. We find that outcome control and capability control promote, whereas outcome control mitigates salesperson commitment to the organizations, and both sales cycle uncertainty and behavioral content uncertainty moderate the relationship between sales controls and salesperson commitment. In general, the paper clarifies and provides a more thorough understanding about the influences of different types of sales control mechanisms on salesperson commitment to the organizations.

First, outcome-based supervision and capability related behavior control, as we predicted, strengthen salespersons' commitment to the organizations. Such findings are consistent with prior studies in sales control literature that hold a negative view of outcome control [12] and a positive view of capability control [68]. In addition to the main effects of those two control mechanisms, we find that another type of behavior control, i.e., activity control, which focuses on performing the required routine activities, weakens salesperson's commitment. To the best of our knowledge, this finding is new in the literature in detailing how different types of behavior-based control function differently in salesperson commitment management. Specifically, whereas prior literature has noticed the distinctive functions between capability control and activity control [58], few empirical tests about the different impacts of the two types of behavior controls on commitment are presented up to now. In this study, we find that activity control harms whereas capability control promotes salesperson commitment.

Second, the direct impacts of sales control mechanisms on salesperson commitment are moderated by behavioral uncertainty. Our empirical results, based on a sample of 208 salespersons in China, suggest that outcome control and capability control increase whereas activity control decreases salesperson commitment, thus stressing the importance to distinguish between activity and capability control. We also find that the main effects are moderated by behavior uncertainty. Although prior studies have identified many contingent factors on the relations between sales control mechanisms and salesperson performance (e.g., [22,25]) they have largely ignored the role of behavioral uncertainty. As suggested by Williamson [27], behavior control significantly affects the power of control mechanisms and plays an important role in selecting optimal control structure. However, prior literature paid limited attention to this contingent factor. Filling this gap, our study depicts the moderating role of behavior control on the relation between sales control mechanisms and salesperson commitment. 
Finally, behavioral uncertainty might include two sub-types, namely sales cycle uncertainty and behavioral content uncertainty. The former focuses on the time period for assessment whereas the latter focuses on the reasonability of the evaluative content set by the manager. The two types of behavioral uncertainty have different moderating roles on the relation between sales controls and commitment. Prior studies have noticed the existence of different types of behavioral uncertainty, but they focused either on sales cycle uncertainty [44] or evaluative content uncertainty [42]. Our paper details the difference between the two types of uncertainty. Specifically, we find that sales cycle uncertainty weakens whereas behavioral content uncertainty strengthens the positive link between outcome control and salesperson commitment as well as the negative relation between activity control and commitment. Besides, both sales cycle uncertainty and behavioral content uncertainty strengthen the positive relationship between capability control and commitment. Such findings extend the behavioral uncertainty studies in transactional cost theory to some extent.

\subsection{Theoretical Contributions}

The paper carries three theoretical contributions to the sales force management literature. First, the paper categorizes behavior control into activity control and capability control following Challagalla and Shervani [21], and find opposite effects of the two types of behavior controls on salesperson commitment. Although prior researchers have emphasized on the importance to distinguish activity control from capability control, most extant research still treated behavior control as an uni-dimensional construct when studying its main effect on commitment. That may lead to misleading conclusions. Our study, by explicitly modeling the relationship between three control mechanisms (outcome, activity and capability control) and salesperson commitment, finds that activity control impedes whereas capability and outcome controls promote commitment. These findings provide a more nuanced understanding about the direct effects of sales controls on salesperson commitment.

Second, this paper introduces behavior uncertainty as a moderator influencing the relationship between sales controls and commitment. Although efforts have been made by prior researchers to identify variables that moderate or mediate the effect of sales controls [23-25], an important contextual factor, namely behavioral uncertainty, is overlooked. According to the transaction cost theory, both the external environment uncertainty and internal behavior uncertainty play significant roles in choosing the optimal control mechanism [27]. However, prior literature focuses more on environment uncertainty but has paid limited attention to behavior uncertainty. Thereby, another contribution of our research is to advance a contingency model depicting behavioral uncertainty as an important moderating variable between sales force controls and salesperson commitment.

Third, extending the line of work on behavioral uncertainty by researchers in transaction cost literature $[43,45]$, this paper further splits behavioral uncertainty into two dimensions, namely sales cycle uncertainty and behavioral content uncertainty, and investigates their different moderating effects respectively. Specifically, we find that the impacts of outcome control and activity control on commitment were weakened by sales cycle uncertainty but strengthened by behavioral content uncertainty. We also find that both kinds of behavioral uncertainty could strengthen the relationship between capability control and salesperson commitment. Although prior studies in both transaction cost theory and behavioral economy have noticed the difference between evaluative cycle uncertainty and evaluation content uncertainty [28,45], we find no empirical evidence of this distinction. To the best of knowledge, most researchers focus on either content uncertainty or sales cycle uncertainty when studying behavioral uncertainty. Our empirical findings provide researchers with deeper insights about the construction and function of behavioral uncertainty.

\subsection{Managerial Contributions}

This study offers implications for managers looking to increase salesperson organizational commitment by practicing sales force control mechanisms. First, our results suggest that the training-related capability control and the goals-oriented outcome control could enhance salespersons' 
attachment to the organizations, whereas activity control focusing on regulations over routine activities might decrease salesperson commitment. Thereby, managers should notice the different functions among the three types of control mechanism in managing salesperson commitment.

Second, our results also highlight the different moderating functions of the two types of behavioral uncertainty, including sales force uncertainty and behavioral content uncertainty, on the association between sales controls and commitment. Therefore, specific execution of sales force controls should be sensitive to different kinds of behavioral uncertainty. Specifically, when sales cycle is hard to be fixed to a certain period of time, sales managers should focus more on activity control and capability control but emphasize less on outcome control. In contrast, managers could focus more on outcome control if sales cycle uncertainty is low. Moreover, when it is difficult to measure a salesperson's individual contribution with reasonable indicators, sales managers should perform less activity control, and focus more on outcome control and capability control. On the contrary, managers should practice more activity control when behavioral content uncertainty is low.

\subsection{Limitations and Future Research}

There might be some limitations of this study, providing directions for further research. First, the study context might be considered as a limitation, since Chinese culture which is characterized by collectivism and high-power distance may result in unintended effects on the model relationships [69]. Whether and to what degree cultural factors affect the construct relationships in our research model remains an open question and need to be addressed through cross-cultural studies in future research. Second, there might be some intermediary constructs in our research model, and future research may explore the mechanism by involving intermediaries such as role ambiguity [70] and intrinsic or extrinsic motivation [68]. Third, the conceptual framework of this research does not incorporate the most controversial outcomes of sales controls-opportunism, job satisfaction and end-performance. Future studies could investigate the moderating role of behavioral uncertainty on the relationship between sales force controls and those outcomes to explain the conflicting results in prior literature. Fourth, this study focuses solely on formal control mechanism while leaving the role of informal control such as socialization between sales reps and managers unexplored. Future studies could investigate the interaction effects among different types of control mechanisms. Fifth, the utilization of self-reported measures is another limitation of our research. Future researchers could collect two-sided data from both the salesperson and their manager, and compare the salespeople's self-reports with their manager's evaluation. Moreover, larger sample size and the combination of different methodologies such as field study and experiments [71] are encouraged to increase the objectivity and significance of the empirical findings.

Author Contributions: M.L. developed the research model, collected the data and wrote the original draft. L.P. and G.Z. contributed to reviewing and revising of this manuscript. All authors have read and agreed to the published version of the manuscript.

Funding: This work was founded by the Fundamental Research Funds for the Central Universities in Jilin University (Grant number 2019ZZ019).

Conflicts of Interest: The authors declare no conflict of interest. 


\section{Appendix A}

Table A1. Measures and CFA Analysis Results.

\begin{tabular}{|c|c|c|c|c|}
\hline Variables & $\alpha$ & AVE & CR & Factor Loading \\
\hline \multicolumn{5}{|l|}{ Outcome Control } \\
\hline 1. Specific goals and profit goals are established for my job. & 0.80 & 0.58 & 0.80 & 0.82 \\
\hline 2. My pay increases would suffer if sales volume or market share targets are not met. & & & & 0.73 \\
\hline Activity Control & 0.88 & 0.71 & 0.88 & \\
\hline 1. My manager monitors how I perform the required job activities. & & & & 0.83 \\
\hline $\begin{array}{l}\text { 2. I would be recognized by my supervisor if s/he were pleased with how well I perform sales } \\
\text { activities. }\end{array}$ & & & & 0.85 \\
\hline Capability Control & 0.80 & 0.58 & 0.80 & \\
\hline 1. My manager provides guidance on ways to improve my selling skills and knowledge. & & & & 0.78 \\
\hline 2. My manager assists by suggesting why using a particular sales approach may be useful. & & & & 0.79 \\
\hline 3. I would be commended if I improved my selling skills. & & & & 0.71 \\
\hline Sale Cycle Uncertainty & 0.80 & 0.57 & 0.80 & \\
\hline 1. My sale cycle can be constrained to a specified time period (r). & & & & 0.80 \\
\hline 2. Our manager evaluates salesperson's contribution to the organization in a highly subjective process. & & & & 0.78 \\
\hline 3. It is difficult for our manager to evaluate whether individual salesperson is doing a good job. & & & & 0.78 \\
\hline Salesperson Commitment & 0.82 & 0.60 & 0.82 & \\
\hline 1. I feel a strong sense of belonging to my organization. & & & & 0.80 \\
\hline 2. I feel personally attached to my sales organization. & & & & 0.74 \\
\hline 3. I would be happy to work at my organization until I retire. & & & & 0.79 \\
\hline \multicolumn{5}{|c|}{ Overall Model Fit $\left(\chi^{2} / \mathrm{df}=1.43, p<0.001 ; \mathrm{CFI}=0.97 ; \mathrm{IFI}=0.97 ; \mathrm{TLI}=0.96 ; \mathrm{RMSEA}=0.045\right)$} \\
\hline
\end{tabular}

Notes: $\mathrm{CR}=$ composite reliability, $\mathrm{AVE}=$ average variance extracted, $\mathrm{CFI}=$ comparative fit index, IFI = incremental fit index, TLI = Tacker-Lewis index, and RMSEA = root mean square error of approximation. Unless otherwise specified, all items were scored on five-point Likert scales $(1=$ "strongly disagree" and $5=$ "strongly agree" $)$.

\section{References}

1. Yeo, C.; Hur, C.; Ji, S. The customer orientation of salesperson for performance in Korean market case: A relationship between customer orientation and adaptive selling. Sustainability 2019, 11, 6115. [CrossRef]

2. Mayberry, R.; Boles, J.S.; Donthu, N. An escalation of commitment perspective on allocation-of-effort decisions in professional selling. J. Acad. Mark. Sci. 2018, 46, 879-894. [CrossRef]

3. Valenzuela, L.; Torres, E.; Hidalgo, P.; Farías, P. Salesperson CLV orientation's effect on performance. J. Bus. Res. 2014, 67, 550-557. [CrossRef]

4. Castro-González, S.; Bande, B.; Fernández-Ferrín, P. Responsible leadership and salespeople's creativity: The mediating effects of CSR perceptions. Sustainability 2019, 11, 2053. [CrossRef]

5. Hartmann, N.N.; Rutherford, B.N.; Hamwi, G.A.; Friend, S.B. The effects of mentoring on salesperson commitment. J. Bus. Res. 2013, 66, 2294-2300. [CrossRef]

6. Angle, H.L.; Perry, J.L. An empirical assessment of organizational commitment and organizational effectiveness. Adm. Sci. Q. 1981, 26,1-14. [CrossRef]

7. Grego-Planer, D. The relationship between organizational commitment and organizational citizenship behaviors in the public and private sectors. Sustainability 2019, 11, 6395. [CrossRef]

8. Wombacher, J.; Felfe, J. The interplay of team and organizational commitment in motivating employees' interteam conflict handling. Acad. Manag. J. 2017, 60, 1554-1581. [CrossRef]

9. Evans, K.R.; Landry, T.D.; Li, P.C.; Zou, S. How sales controls affect job-related outcomes: The role of organizational sales-related psychological climate perceptions. J. Acad. Mark. Sci. 2007, 35, 445-459. [CrossRef]

10. Cravens, D.W.; Lassk, F.G.; Low, G.S.; Marshall, G.W.; Moncrief, W.C. Formal and informal management control combinations in sales organizations: The impact on salesperson consequences. J. Bus. Res. 2004, 57, 241-248. [CrossRef]

11. Pettijohn, C.; Pettijohn, L.S.; Taylor, A.J.; Keillor, B.D. Are performance appraisals a bureaucratic exercise or can they be used to enhance sales-force satisfaction and commitment? Psychol. Mark. 2001, 18, 337-364. [CrossRef] 
12. Crosno, J.L.; Brown, J.R. A meta-analytic review of the effects of organizational control in marketing exchange relationships. J. Acad. Mark. Sci. 2015, 43, 297-314. [CrossRef]

13. Kim, S.K.; Tiwana, A. Chicken or egg? Sequential complementarity among salesforce control mechanisms. J. Acad. Mark. Sci. 2016, 44, 316-333. [CrossRef]

14. Purohit, B. Salesperson performance: Role of perceived overqualification and organization type. Mark. Intell. Plan. 2018, 36, 79-92. [CrossRef]

15. Jaworski, B.J. Toward a theory of marketing control: Environmental context, control types, and consequences. J. Mark. 1988, 52, 23-39. [CrossRef]

16. Bonner, J.M. The influence of formal controls on customer interactivity in new product development. Ind. Mark. Manag. 2005, 34, 63-69. [CrossRef]

17. Kim, S.K.; Jung, Y.S. Regaining control of salesforce. Ind. Mark. Manag. 2018, 73, 84-98. [CrossRef]

18. Hwan Choi, N.; Dixon, A.L.; Jung, J.M. Dysfunctional behavior among sales representatives: The effect of supervisory trust, participation, and information controls. J. Pers. Sell. Sales Manag. 2004, 24, 181-198.

19. Lusch, R.F.; Jaworski, B.J. Management controls, role stress, and retail store manager performance. J. Retail. 1991, 67, 397.

20. Malek, S.L.; Sarin, S.; Jaworski, B.J. Sales management control systems: Review, synthesis, and directions for future exploration. J. Pers. Sell. Sales Manag. 2018, 38, 30-55. [CrossRef]

21. Challagalla, G.N.; Shervani, T.A. Dimensions and types of supervisory control: Effects on salesperson performance and satisfaction. J. Mark. 1996, 60, 89-105. [CrossRef]

22. Rindfleisch, A.; Heide, J.B. Transaction cost analysis: Past, present, and future applications. J. Mark. 1997, 61, 30-54. [CrossRef]

23. Cogin, J.A.; Williamson, I.O. Standardize or customize: The interactive effects of HRM and environment uncertainty on MNC subsidiary performance. Hum. Resour. Manag. 2014, 53, 701-721. [CrossRef]

24. Verano-Tacoronte, D.; Melián-González, S. Human resources control systems and performance: The role of uncertainty and risk propensity. Int. J. Manpower. 2008, 29, 161-187. [CrossRef]

25. Challagalla, G.; Shervani, T.; Huber, G. Supervisory orientations and salesperson work outcomes: The moderating effect of salesperson location. J. Pers. Sell. Sales Manag. 2000, 20, 161-171.

26. Anderson, E. The salesperson as outside agent or employee: A transaction cost analysis. Mark. Sci. 2008, 27, 70-84. [CrossRef]

27. Williamson, O.; Williamson, O.; Ghani, T.; Ghani, T. Transaction cost economics and its uses in marketing. J. Acad. Mark. Sci. 2012, 40,74-85. [CrossRef]

28. Plenborg, T. The operating cycle and the information content of earnings and cash flow. Scand. J. Manag. 1998, 14, 273-287. [CrossRef]

29. Anderson, E.; Oliver, R.L. Perspectives on behavior-based versus outcome-based salesforce control systems. J. Mark. 1987, 51, 76-88. [CrossRef]

30. Agarwal, S.; Ramaswami, S.N. Marketing controls and employee responses: The moderating role of task characteristics. J. Acad. Mark. Sci. 1993, 21, 293-306. [CrossRef]

31. de Oliveira Santini, F.; Vieira, V.A.; Ladeira, W.J.; Sampaio, C.H. Behaviour-based and outcome-based control systems: A meta-analytic Study. Can. J. Adm. Sci. 2019, 36, 149-162. [CrossRef]

32. Lewis, M.W.; Welsh, M.A.; Dehler, G.E.; Green, S.G. Product development tensions: Exploring contrasting styles of project management. Acad. Manag. J. 2002, 45, 546-564.

33. Mowday, R.T.; Steers, R.M.; Porter, L.W. The measure of organizational commitment. J. Vocat. Behav. 1979, 14, 224-247. [CrossRef]

34. Allen, N.J.; Meyer, J.P. The measurement and antecedents of affective, continuance and normative commitment to the organization. J. Occup. Organ. Psychol. 1990, 63, 1-18. [CrossRef]

35. Meyer, J.P.; Alien, N.J. A three-component conceptualization of organizational commitment. Hum. Resour. Manag. Rev. 1991, 1, 61-89. [CrossRef]

36. Boles, J.; Madupalli, R.; Rutherford, B.; Wood, J.A. The relationship of facets of salesperson job satisfaction with affective organizational commitment. J. Bus. Ind. Mark. 2007, 22, 311-321. [CrossRef]

37. Whitener, E.M. Do "high commitment" human resource practices affect employee commitment? A cross-level analysis using hierarchical linear modeling. J. Manag. 2001, 27, 515-535. [CrossRef]

38. Brammer, S.; Millington, A.; Rayton, B. The contribution of corporate social responsibility to organizational commitment. Int. J. Hum. Resour. Manag. 2007, 18, 1701-1719. [CrossRef] 
39. Seifert, M.; Brockner, J.; Bianchi, E.C.; Moon, H. How workplace fairness affects employee commitment. MIT Sloan Manag. Rev. 2016, 57, 14-17.

40. Noordewier, T.G.; John, G.; Nevin, J.R. Performance outcomes of purchasing arrangements in industrial buyer-vendor relationships. J. Mark. 1990, 54, 80-93. [CrossRef]

41. Macher, J.T.; Richman, B.D. Transaction cost economics: An assessment of empirical research in the social sciences. Bus. Politics 2008, 10,1-63. [CrossRef]

42. Stump, R.L.; Heide, J.B. Controlling supplier opportunism in industrial relationships. J. Mark. Res. 1996, 33, 431-441. [CrossRef]

43. Chandler, G.N.; McKelvie, A.; Davidsson, P. Asset specificity and behavioral uncertainty as moderators of the sales growth-Employment growth relationship in emerging ventures. J. Bus. Ventur. 2009, 24, 373-387. [CrossRef]

44. John, G.; Weitz, B.A. Salesforce compensation: An empirical investigation of factors related to use of salary versus incentive compensation. J. Mark. Res. 1989, 26, 1-14. [CrossRef]

45. John, G.; Weitz, B.A. Forward integration into distribution: An empirical test of transaction cost analysis. J. Law Econ. Organ. 1988, 4, 337-355.

46. Eisenhardt, K.M. Agency theory: An assessment and review. Acad. Manag. Rev. 1989, 14, 57-74. [CrossRef]

47. Niesten, E.; Jolink, A. Incentives, opportunism and behavioral uncertainty in electricity industries. J. Bus. Res. 2012, 65, 1031-1039. [CrossRef]

48. Latham, G.P.; Locke, E.A. Employee motivation. In Handbook of Organizational Behavior; Sage Publications: Newbury Park, CA, USA, 2008.

49. Joshi, A.W.; Randall, S. The indirect effects of organizational controls on salesperson performance and customer orientation. J. Bus. Res. 2001, 54, 1-9. [CrossRef]

50. Fang, E.; Evans, K.R.; Landry, T.D. Control systems' effect on attributional processes and sales outcomes: A cybernetic information-processing perspective. J. Acad. Mark. Sci. 2005, 33, 553-574. [CrossRef]

51. Wang, G.; Dou, W.; Zhou, N. The interactive effects of sales force controls on salespeople behaviors and customer outcomes. J. Pers. Sell. Sales Manag. 2012, 32, 225-243. [CrossRef]

52. Miao, C.F.; Evans, K.R. The interactive effects of sales control systems on salesperson performance: A job demands-resources perspective. J. Acad. Mark. Sci. 2013, 41, 73-90. [CrossRef]

53. Latham, G.P.; Locke, E.A. Self-regulation through goal setting. Organ. Behav. Hum. Des Decis. Proc. 1991, 50, 212-247. [CrossRef]

54. Avlonitis, G.J.; Panagopoulos, N.G. Exploring the influence of sales management practices on the industrial salesperson: A multi-source hierarchical linear modeling approach. J. Bus. Res. 2007, 60, 765-775. [CrossRef]

55. Liu, S.; Wang, L. User liaisons' perspective on behavior and outcome control in IT projects: Role of IT experience, behavior observability, and outcome measurability. Manag. Decis. 2014, 52, 1148-1173. [CrossRef]

56. Loi, R.; Hang-Yue, N.; Foley, S. Linking employees' justice perceptions to organizational commitment and intention to leave: The mediating role of perceived organizational support. J. Occup. Organ. Psychol. 2006, 79, 101-120. [CrossRef]

57. Bennett, R. Guanxi and salesforce management practices in China. Asia. Pac. Bus. Rev. 1999, 5, 73-93. [CrossRef]

58. Brislin, R.W. Translation and content analysis of oral and written materials. Methodology 1980, 2, 389-444.

59. Jaworski, B.J.; MacInnis, D.J. Marketing jobs and management controls: Toward a framework. J. Mark. Res. 1989, 26, 406-419. [CrossRef]

60. Churchill, G.A. A paradigm for developing better measures of marketing constructs. J. Mark. Res. 1979, 16, 64-73. [CrossRef]

61. Meyer, J.P.; Allen, N.J. Commitment in the Workplace; Sage Publications: Thousand Oaks, CA, USA, 1997.

62. Im, S.; Chung, Y.W.; Yang, J.Y. Employees' participation in corporate social responsibility and organizational outcomes: The moderating role of person-CSR fit. Sustainability 2017, 9, 28. [CrossRef]

63. Netemeyer, R.G.; Brashear-Alejandro, T.; Boles, J.S. A cross-national model of job-related outcomes of work role and family role variables: A retail sales context. J. Acad. Mark. Sci. 2004, 32, 49-60. [CrossRef]

64. Podsakoff, P.M.; MacKenzie, S.B.; Lee, J.Y.; Podsakoff, N.P. Common method biases in behavioral research: A critical review of the literature and recommended remedies. J. Appl. Psychol. 2003, 885, 10-37. [CrossRef] [PubMed] 
65. Fornell, C.; Larcker, D.F. Evaluating structural equation models with unobservable variables and measurement error. J. Mark. Res. 1981, 18, 39-50. [CrossRef]

66. Hair, J.F.; Anderson, R.E.; Tatham, R.L.; Black, W.C. Multivariate Data Analysis with Readings; Macmillan: New York, NY, USA, 1992.

67. Aiken, L.S.; West, S.G.; Reno, R.R. Multiple Regression: Testing and Interpreting Interactions; Sage Publications: Newbury Park, CA, USA, 1991.

68. Miao, C.F.; Evans, K.R. Motivating industrial salesforce with sales control systems: An interactive perspective. J. Bus. Res. 2014, 67, 1233-1242. [CrossRef]

69. Hofstede, G.; Eckhardt, G. Culture's Consequences: Comparing Values, Behaviors, Institutions and Organisations across Nations: Book Review; Sage Publications: Newbury Park, CA, USA, 2002.

70. Rigopoulou, I.; Theodosiou, M.; Katsikea, E.; Perdikis, N. Information control, role perceptions, and work outcomes of boundary-spanning frontline managers. J. Bus. Res. 2012, 65, 626-633. [CrossRef]

71. McGrath, J.E. Dilemmatics: The study of research choicesand dilemmas. In Judgment calls in research; Martin, J., McGrath, J.E., Kulka, R.A., Eds.; Sage Publications: Newbury Park, CA, USA, 1982.

(C) 2020 by the authors. Licensee MDPI, Basel, Switzerland. This article is an open access article distributed under the terms and conditions of the Creative Commons Attribution (CC BY) license (http://creativecommons.org/licenses/by/4.0/). 